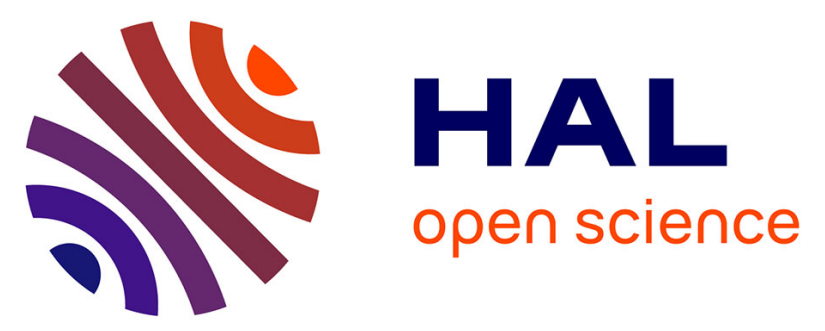

\title{
Finite element analysis of vulnerable atherosclerotic plaques: A comparison of mechanical stresses within carotid plaques of acute and recently symptomatic patients with carotid artery disease
}

Umar Sadat, Zhi-Yong Li, Victoria E Young, Martin J Graves, Jonathan R Boyle, Elizabeth A Warburton, Kevin Varty, Eoin O'Brien, Jonathan H Gillard

\section{- To cite this version:}

Umar Sadat, Zhi-Yong Li, Victoria E Young, Martin J Graves, Jonathan R Boyle, et al.. Finite element analysis of vulnerable atherosclerotic plaques: A comparison of mechanical stresses within carotid plaques of acute and recently symptomatic patients with carotid artery disease. Journal of Neurology, Neurosurgery and Psychiatry, 2010, 81 (3), pp.286. 10.1136/jnnp.2009.190363 . hal00552792

\author{
HAL Id: hal-00552792 \\ https://hal.science/hal-00552792
}

Submitted on 6 Jan 2011

HAL is a multi-disciplinary open access archive for the deposit and dissemination of scientific research documents, whether they are published or not. The documents may come from teaching and research institutions in France or abroad, or from public or private research centers.
L'archive ouverte pluridisciplinaire HAL, est destinée au dépôt et à la diffusion de documents scientifiques de niveau recherche, publiés ou non, émanant des établissements d'enseignement et de recherche français ou étrangers, des laboratoires publics ou privés. 
Finite element analysis of vulnerable atherosclerotic plaques: A

comparison of mechanical stresses within carotid plaques of acute and

recently symptomatic patients with carotid artery disease

Umar Sadat MRCS, MPhil ${ }^{1,2}$

Zhi-Yong Li PhD ${ }^{1}$

Victoria E Young MRCS, MPhil ${ }^{1}$

Martin J Graves MSc ${ }^{1}$

Jonathan R Boyle MD, FRCS ${ }^{2}$

Elizabeth L Warburton FRCP ${ }^{3}$

Kevin Varty MD, FRCS ${ }^{2}$

Eoin O'Brien FRCP ${ }^{3}$

Jonathan H Gillard MD, FRCR ${ }^{1}$

${ }^{1}$ University Department of Radiology, Addenbrooke's Hospital, University of Cambridge, Cambridge, United Kingdom; ${ }^{2}$ Cambridge Vascular Unit, Addenbrooke's Hospital, Cambridge, United Kingdom; ${ }^{3}$ Department of Stroke Medicine, Addenbrooke's Hospital, Cambridge, United Kingdom

\section{Corresponding Author:}

Dr. Umar Sadat

Box 218, University Department of Radiology

Addenbrooke's Hospital

Cambridge CB2 0QQ, UK

Tel: $+44(0) 1223767834$

Fax: $+44(0) 1223330915$

Email: sadat.umar@gmail.com 


\section{Keywords:}

Mechanical stress, atherosclerosis, transient ischaemic attack, carotid stenosis, stroke

\section{Word count:}

2734

\section{Running Head:}

Mechanical stress of vulnerable carotid plaques 


\begin{abstract}
:
Objectives

There is considerable evidence that patients with carotid artery stenosis treated immediately after the ischaemic cerebrovascular event have a better clinical outcome than those who get delayed treatment. Biomechanical assessment of carotid plaques using high resolution magnetic resonance imaging (MRI) can help examine the relationship between the timing of carotid plaque symptomology and maximum simulated plaque stress concentration.
\end{abstract}

\title{
Methods
}

Fifty patients underwent high-resolution multisequence in vivo MRI of their carotid arteries. Acute symptomatic patients $(n=25)$ underwent MRI within 72 hours of the onset of ischaemic cerebrovascular symptoms, whereas recently symptomatic patients $(n=25)$ underwent MRI from 2 to 6 weeks after the onset of symptoms. Stress analysis was performed based on the geometry derived from in vivo MRI of the symptomatic carotid artery at the point of maximum stenosis. The peak stresses within the plaques of the two groups were compared.

\section{Results}

Patient demographics were comparable for both groups. All the patients in recently symptomatic group had severe carotid stenosis in contrast to acute symptomatic patients who had predominantly mild to moderate carotid stenosis. The simulated maximum stresses in acute symptomatic patients was significantly higher than in recently symptomatic patients 
[median (interquartile range): $313 \times 10^{4} \mathrm{dynes} / \mathrm{cm}^{2}$ (295-382) vs. $252 \times 10^{4} \mathrm{dynes} / \mathrm{cm}^{2}(236-$ 311), $\mathrm{p}=0.02]$.

\section{Conclusions}

Patients have extremely unstable, high-risk plaques, with high stresses, immediately after an acute cerebrovascular event, even at lower degrees of carotid stenoses. Biomechanical stress analysis may help us refine our risk-stratification criteria for the management of patients with carotid artery disease in future.

\section{Keywords:}

Mechanical stress, atherosclerosis, transient ischaemic attack, carotid stenosis, stroke 


\section{Introduction:}

Over 150,000 people suffer minor strokes and transient ischaemic attacks (TIA) in the United Kingdom, but only $35 \%$ patients are seen and investigated within seven days.[1] There is a $6.7 \%$ risk of having a stroke in the first 2 days and a $13.4 \%$ risk within the first 4 weeks after TIA.[2] Investigating and treating these patients within 24 hours can produce an $80 \%$ reduction in the number of patients who proceed to have a full stroke.[3] Two thirds of the strokes are ischaemic in origin and more than half of them are caused by the rupture of atherosclerotic carotid plaques. Large randomized controlled trials like the North American Symptomatic Carotid Endarterectomy Trial (NASCET) and European Carotid Surgery Trial (ECST) have shown significant benefit from carotid endarterectomy (CEA) for patients with $>70 \%$ stenosis and moderate benefits for moderate stenosis group.[4-7] Though there may be a $7 \%$ risk of 30 day death/stroke following CEA if done within 48 hours and slightly higher risk of $10 \%$ if operated within 14 days, the operation will prevent approximately 150 strokes at 6 years per 1000 CEA.[8] Only 100 strokes would be prevented if CEA is delayed for more than 4 weeks and operated with $3 \%$ perioperative risk. $[2,9]$ This has led to drastic changes in National Stroke Strategy in UK, which calls for emergency initial assessment of carotid arteries within 24 hours and emergency carotid intervention for patients who are neurologically stable ideally within 48 hours.[10]

High-resolution magnetic resonance imaging (MRI) can assist the assessment of the morphological and biomechanical characteristics of atheromatous plaques.[11, 12] Recently, we have demonstrated that high resolution MRI can be used to identify morphological 
characteristics of plaques when they are most unstable e.g. immediately after an acute cerebrovascular ischaemic event.[13] In this paper, we examine whether biomechanical assessment based on MRI can assist the differentiation of different subsets of symptomatic patients

\section{Methods:}

\section{Patients}

Fifty patients having symptomatic carotid atherosclerotic disease underwent high resolution MRI of their carotid arteries in a 1.5Tesla MRI system (Signa HDx GE Healthcare, Waukesha, WI) with a 4- channel phased-array neck coil (PACC, Machnet BV, Elde, The Netherlands). Half of them were acute symptomatic i.e. they underwent MRI within 72 hours of the onset of ischaemic cerebrovascular symptoms. The other half were recently symptomatic i.e. they had onset of symptoms from 2 to 6 weeks before undergoing MR imaging of their carotid arteries. All patients had either a TIA or minor non-disabling stroke, diagnosed by a stroke physician. A retinal TIA was defined as a partial or complete visual field loss in one eye of ischemic origin lasting less than $24 \mathrm{~h}$, with a hemispheric TIA being defined as a focal cerebral dysfunction of ischemic origin lasting less than 24 h.[14] A minor stroke was defined as a neurological dysfunction of ischemic origin with deficits persisting longer than $24 \mathrm{~h}$, but with a Rankin score $\leq 3$.[14] The MR study protocol was reviewed and approved by the regional research ethics committee and all patients gave written, informed consent. Patients presenting $>72 \mathrm{hrs}$ and within 2 weeks of onset of acute symptoms were excluded from the study. This was done to enable a clear differentiation between the two groups on the post-stroke/TIA timeline. 
Imaging techniques

Movement artifact was minimized using a dedicated vacuum-based head restraint system (VAC-LOK Cushion, Oncology Systems Limited, UK) to fix the head and neck in a comfortable position and allow close apposition of the surface coils. After an initial coronal localizer sequence, axial 2D time-of-flight (TOF) MR angiography was performed to identify the location of the carotid bifurcation and the region of maximum stenosis on each side. Axial images were acquired through the common carotid artery $12 \mathrm{~mm}$ ( 4 slices) below the carotid bifurcation to a point $12 \mathrm{~mm}$ (4 slices) distal to the extent of the stenosis identified on the TOF sequence. This method ensured that the entire carotid plaque was imaged.[15]

The following MRI protocol was used to delineate various plaque components such as fibrous cap (FC), lipid-rich necrotic core (LR/NC): $\mathrm{T}_{1}$ weighted (repetition time/echo time: $1 * \mathrm{RR} / 7.8 \mathrm{~ms}$ ) with fat saturation; $\mathrm{T}_{2}$ weighted (repetition time/echo time: $2 * \mathrm{RR} / 100 \mathrm{~ms}$ ) with fat saturation; and short tau inversion recovery (STIR) (repetition time/echo time/inversion time: $2 * \mathrm{RR} / 46 \mathrm{~ms} / 150 \mathrm{~ms}$ ).[11]. The field of view was $10 \times 10 \mathrm{~cm}$ and matrix size $256 \times 256$. The inplane spatial resolution achieved was of the order of $0.39 \times 0.39 \mathrm{~mm}$.

Plaque components of the symptomatic carotid artery were manually delineated by two experienced MR readers (US, VEY) using CMR Tools (London, UK). Once delineated, control vertices were exported from the segmentation software and were imported into a specialist engineering package (Patran 2008 r1, MSC Software Corp, Santa Ana, Calif and ABAQUS 6.8, SIMULIA Europe Netherlands), where the contours were reconstructed using a closed B-spline technique to form the geometry for mesh generation. The degree of carotid stenosis was calculated using ECST criteria. 


\section{Material mechanical properties:}

In this study, the mechanical behavior of plaque components was modeled as hyperelastic using a two-term Ogden strain energy formulation simulating the nonlinear stress strain characteristics of plaque components.[16]

The two-term strain energy form was:

$$
W=\sum_{i=1}^{N} \frac{\mu_{i}}{\alpha_{i}} J^{-\frac{\alpha_{i}}{3}}\left(\lambda_{1}^{\alpha_{i}}+\lambda_{2}^{\alpha_{i}}+\lambda_{3}^{\alpha_{i}}-3\right)+4.5\left(K^{-\frac{1}{3}}-1\right)^{2}
$$

Where $N$ is the number of terms ( 2 in this simulation), $\lambda_{i}$ are the principle stretch ratios, $J$ is the Jacobian modulus, $K$ is the bulk modulus; $\mu_{i}$ are moduli constants and $\mu_{l=} \mu_{2}$; and $\alpha_{i}$ are exponent constants and $\alpha_{1}=\alpha_{2}$. The specific two-term model used has been validated in engineering experiments using human atheromatous tissue. They refer to the stiffness of the material, which describes the behavior of the material when placed under a force. Values of these terms for the various carotid plaque components were chosen based on previous studies.[16, 17]

\section{Computational modeling:}

The investigator responsible for the finite element analysis (ZYL) was not involved in the acquisition of subject MR data and image segmentation and thus had no knowledge of the degree of luminal stenosis or the timing of symptoms in any of the subjects. An internal pulse pressure waveform as measured noninvasively using tonometry was applied uniformly on the lumen surface in this numeric simulation. The pressure on the outside vessel surface was assumed to be negligible, and the plaque was considered stress free at zero pressure (no 
residual stress).The numeric simulation was performed using the ABAQUS 6.8 finite element analysis package. Contour plots of von Mises stress were displayed using ABAQUS postprocessing. von Mises stresses are those predicted within the plaque itself as a result of interaction between the plaque components. Please note that the mechanical stress is unrelated and is an order of magnitude greater than the wall shear stresses commonly referred to in vascular biology. Wall shear stresses are produced as a result of the action of blood pressure against the vessel wall and are independent of plaque mechanical properties. These shear stresses may be important in the pathology of endothelial dysfunction, but they are too small to be considered in purely mechanical simulation. Slices at the point of maximum stenosis for each patient were simulated and maximum stresses were recorded.

\section{Statistical analysis:}

The patient demographics were compared using the Mann-Whitney $U$ test and the Fisher exact test. The analysis of variance was validated using Shapiro Wilk W test. A two-tailed unpaired Student $t$ test was used to determine the significance of any differences in the peak stress between plaques from the two groups. A p-value of less than 0.05 was deemed significant.

\section{Results:}

Patient demographics were comparable for both groups (average age: $76 \pm 12$ vs. $71 \pm 9$ years, $\mathrm{p}=0.5$; hypertension: $\mathrm{p}=0.44$; diabetes: $\mathrm{p}=0.08$ ). All patients in the recently symptomatic group $(n=25)$ had severe carotid stenosis $(>70 \%)$ in contrast to acute symptomatic patients $(n=25), 76 \%(n=19)$ of whom had mild to moderate carotid stenosis $(\geq 30 \%$ to $\leq 70 \%)$. The remaining 24\% $(n=6)$ had severe stenosis. The simulated maximum stress in the acute symptomatic patients was significantly higher than in the recently symptomatic patients 
\{median [interquartile range (IQR)]: $313 \times 10^{4}$ dynes $/ \mathrm{cm}^{2}(295-382)$ vs. $252 \times 10^{4}$ dynes $/ \mathrm{cm}^{2}$ (236-311), $\mathrm{p}=0.02\}$. The patients with moderate stenosis in the acute symptomatic group $(n=19)$, showed higher maximum stress as compared to the recently symptomatic patients [median (IQR): $313 \times 10^{4}$ dynes $/ \mathrm{cm}^{2}$ (297-368) vs. $252 \times 10^{4}$ dynes $/ \mathrm{cm}^{2}$ (236-311), p=0.04).

The median maximum stress for the patients with severe stenosis in acute symptomatic group $(n=6)$ was $373.6 \times 10^{4}$ dynes/cm² (IQR: $\left.314-397\right)$ which was though higher than the recently symptomatic patients but did not reach statistical significance $(\mathrm{p}=0.07)$. This may have been due to lower number of patients in this group. The high stress concentrations were found at the shoulder regions of the plaque and at the MRI-identified regions of plaque rupture (using previously published MRI- based plaque characterization criteria.[13] A comparison between the stresses in acute and recently symptomatic patients is shown in Figure 1, 2 respectively.

\section{Discussion:}

This study suggest, that high resolution MRI can be used to assess the relationship between biomechanical characteristics of plaque and timing of symptomology in addition to the already determined relationship between plaque morphology and timing of symptomology.[13] This study used in vivo MRI and finite element analysis, considering plaque components as nonlinearly elastic, to determine the mechanical stresses within carotid plaques and evaluated whether acute symptomatic carotid plaques had higher internal stresses than recently symptomatic ones. The division of symptomatic patients was done to investigate the concept that patients are at much higher risk of recurrent ischaemic events immediately after the initial attack than later on. The results suggest that the maximum stresses within the plaques of acute symptomatic patients are higher than those of recently symptomatic patients, and thus, biomechanical profiling is, to some extent, able to distinguish 
between the clinical groups. This illustrates that atherosclerotic plaques have high stresses immediately after the acute cerebrovascular event in addition to having a thinner fibrous cap; which may be ruptured or eroded. The prevalence is less in recently symptomatic patients, thereby highlighting the fact that acute symptomatic patients should be treated immediately and aggressively. Naylor and Rothwell et al have already demonstrated the significant risk reduction resulting from aggressive management of such patients.[3, 8]

The utility of the carotid plaque stress analysis highlights the efficacy of non-invasive biomechanical modelling in providing insight into the underlying patho mechanics of plaque rupture and symptomology. This analysis uses geometric and morphologic data derived from in vivo MRIs of the carotid bifurcation to conduct finite element analysis on plaque rupture analysis. The methodology and other applications have previously been published by our group. $[18,19]$ Our group has already used this biomechanical model to differentiate symptomatic and asymptomatic patients.[20] This is in contrast to previous studies, which use the geometry derived from histology.[21] and ex vivo MRI.[22] The main limitation of those techniques is that changes in atheroma as a result of endarterectomy and histological fixation which will have a significant impact on the simulated stress distributions. The structural analysis used a nonlinear Ogden model to simulate the nonlinear mechanical response of plaque components. It is important to have a better understanding of the physical properties of the components of atheromatous plaque, as stresses predicted within the plaque will differ considerably depending on which model is chosen and what parameters are used. Previous reports have confirmed the observations described here in that lipid pools with low Young's moduli (this refers to the deformation produced per unit force exerted) will result in higher peak stresses.[23] Such biomechanical modeling naturally assumes that the plaque components are homogeneous, with a uniform and predictable response to mechanical stress. Clearly, cellular material is much more complex than this, and it is entirely plausible that the 
mechanical properties of lipid core, for example, will alter according to its individual cellularity and extent of lipid esterification. Likewise, the fibrous cap contains not only collagen fibers but also smooth muscle like cells that have been shown to undergo apoptosis in vulnerable plaque. This process is likely to weaken the cap at these points and dynamically alter the Young's modulus of the tissue at that location. Despite this simplified model, however, it would reasonable to speculate that these differences would only serve to increase the predicted differences between patient groups rather than decrease them.

Luminal stenosis is an important factor for risk assessment of patients with carotid atheroma, and it has been the traditional clinical measure of risk. Maximum stress is normally predicted at the most stenotic location within a single plaque, although when comparing two plaques, it is not necessarily true that the bigger the plaque, the higher the stress. In this study it was observed that patient with mild to moderate stenosis had higher plaque stress as compared to patients with severe stenosis in recently symptomatic group. Moreover, it was found that patients with severe stenosis in acute symptomatic group had slightly higher plaque stress than those in the recently symptomatic group. Although this did not reach statistical significance, this may have been because of smaller number of patients. But it further reiterates the fact that plaque stress can increase even at lower degrees of luminal stenosis. More research studies with larger population size are required for better understanding of this phenomenon.

\section{Limitations:}

Because this was not a flow-interaction-coupled model, it was not possible to simulate the effect of turbulent flow and a pressure drop across a stenosis, which of course will affect the applied load. Local pressure distribution cannot currently be directly determined from non- 
invasive imaging. Plaque calcification was not considered in this study and is therefore an additional limitation of the analysis. Calcium can be an important factor in the consideration of stress distributions within atheroma.[24] There is, however, debate in the literature about its role as protective against or a risk factor for plaque rupture. Calcium produces little signal on conventional MRI because its T2 decay is extremely rapid; therefore, MRI is not currently the best modality to look at plaque calcification. Our cohort did not show many foci of calcification in either group. Histology was not used for comparison with MR images and therefore may be considered a limitation of this study but we have already shown a good correlation in plaque morphology between the two techniques.[25, 26] Most patients in acute symptomatic did not go for CEA due to a lower degree of luminal stenosis; hence histological analysis was not possible. This therefore illustrates that MRI can give important early information about plaque nature instead of waiting for patients to undergo CEA and subsequently to make a histological diagnosis.[13]

\section{Conclusion:}

We have identified differences in stress patterns between acute symptomatic and recently symptomatic plaques in vivo by combining finite element analysis with in vivo highresolution multi-spectral MRI. We have refined previously published models by the introduction of a non-linear two-term Ogden formulation to consider the behavior of plaque components as nonlinearly elastic solids to sub classify symptomatic plaques into acute and recent categories. Maximum plaque stresses were found to be significantly higher in acute symptomatic patients than those in recently symptomatic patients. This highlights the importance of aggressive management of patients, immediately following acute cerebrovascular events. 


\section{Acknowledgments:}

None

\section{License for Publication:}

The Corresponding Author has the right to grant on behalf of all authors and does grant on behalf of all authors, an exclusive licence (or non exclusive for government employees) on a worldwide basis to the BMJ Publishing Group Ltd to permit this article (if accepted) to be published in PMJ and any other BMJPGL products and sublicenses such use and exploit all subsidiary rights, as set out in our licence. (http://group.bmj.com/products/journals/instructionsfor-authors/licence-forms)

\section{Competing interests:}

The authors report no conflict of interest concerning the materials or methods used in this study or the findings specified in this paper.

\section{Disclosure:}

U Sadat is funded by clinical research training fellowship of Medical Research Council (UK) and Royal College of Surgeons of England. This project was also supported by grant from NIHR Biomedical Research Centre. 


\section{Figures legend:}

Figure 1: Stress analysis of an atheromatous carotid plaque of an acute symptomatic patient. Identification of plaque components from in vivo carotid MRI (L: lumen; fibrous cap: yellow arrow; fibrous cap rupture (red arrow), lipid pool: yellow star(*) $\mathrm{T}_{1}$-weighted image (a), STIR image (b.) c: The plaque geometry for FEA - In this reconstruction a lipid pool was assumed(red star) to be present to simulate its pre rupture presence. d: Computed stress contour showing high stress in the plaque rupture region (red arrow) and the shoulder regions (black arrow).

\section{Figure 2:}

Stress analysis of an atheromatous carotid plaque of a recently symptomatic patient. Identification of plaque components from in vivo carotid MRI (L: lumen; fibrous cap: yellow arrow; shoulder regions of the plaque (red arrows), lipid pool: green star $(*) \mathrm{T}_{1}$-weighted image (a), STIR image (b) and $\mathrm{T}_{2}$-weighted image with regions of interest (ROI) (c). d: Computed stress contour showing high stress in the shoulder regions (red arrow). 


\section{References:}

1. Giles MF, Rothwell PM. Substantial underestimation of the need for outpatient services for TIA and minor stroke. Age Ageing. 2007;36(6):676-680.

2. Naylor AR. Time is brain! Surgeon. 2007;5(1):23-30.

3. Rothwell PM, Giles MF, Chandratheva A, Marquardt L, Geraghty O, Redgrave JN, Lovelock CE, Binney LE, Bull LM, Cuthbertson FC, Welch SJ, Bosch S, Alexander FC, Silver LE, Gutnikov SA, Mehta Z. Effect of urgent treatment of transient ischaemic attack and minor stroke on early recurrent stroke (EXPRESS study): a prospective population-based sequential comparison. Lancet. 2007;370(9596):14321442.

4. Beneficial effect of carotid endarterectomy in symptomatic patients with high-grade carotid stenosis. North American Symptomatic Carotid Endarterectomy Trial Collaborators. N Engl J Med. 1991;325(7):445-453.

5. MRC European Carotid Surgery Trial: interim results for symptomatic patients with severe (70-99\%) or with mild (0-29\%) carotid stenosis. European Carotid Surgery Trialists' Collaborative Group. Lancet. 1991;337(8752):1235-1243.

6. Murphy RE, Moody AR, Morgan PS, Martel AL, Delay GS, Allder S, MacSweeney ST, Tennant WG, Gladman J, Lowe J, Hunt BJ. Prevalence of complicated carotid atheroma as detected by magnetic resonance direct thrombus imaging in patients with suspected carotid artery stenosis and previous acute cerebral ischemia. Circulation. 2003;107(24):3053-3058. 
7. Rothwell PM, Eliasziw M, Gutnikov SA, Fox AJ, Taylor DW, Mayberg MR, Warlow $\mathrm{CP}$, Barnett HJ. Analysis of pooled data from the randomised controlled trials of endarterectomy for symptomatic carotid stenosis. Lancet. 2003;361(9352):107-116.

8. Naylor AR. Occam's razor: Intervene early to prevent more strokes! J Vasc Surg. 2008;48(4):1053-1059.

9. Naylor AR. Delay may reduce procedural risk, but at what price to the patient? Eur J Vasc Endovasc Surg. 2008;35(4):383-391.

10. National Stroke Strategy. 2007, http://www.dh.gov.uk/en/Publicationsandstatistics/Publications/PublicationsPolicyAn dGuidance/DH_081062

11. JM UK-I, Tang TY, Patterson A, Graves MJ, Howarth S, Li ZY, Trivedi R, Bowden D, Kirkpatrick PJ, Gaunt ME, Warburton EA, Antoun NM, Gillard JH. Characterisation of carotid atheroma in symptomatic and asymptomatic patients using high-resolution MRI. J Neurol Neurosurg Psychiatry. 2008.

12. Trivedi RA, Li ZY, J UK-I, Graves MJ, Kirkpatrick PJ, Gillard JH. Identifying vulnerable carotid plaques in vivo using high resolution magnetic resonance imagingbased finite element analysis. J Neurosurg. 2007;107(3):536-542.

13. Sadat U, Weerakkody RA, Bowden DJ, Young VE, Graves MJ, Li ZY, Tang TY, Gaunt ME, Hayes PD, Gillard JH. Utility of high resolution MR imaging to assess carotid plaque morphology: A comparison of acute symptomatic, recently symptomatic and asymptomatic patients with carotid artery disease. Atherosclerosis. 2009.

14. Eliasziw M, Kennedy J, Hill MD, Buchan AM, Barnett HJ. Early risk of stroke after a transient ischemic attack in patients with internal carotid artery disease. CMAJ. 2004;170(7):1105-1109. 
15. Howarth SP, Tang TY, Trivedi R, Weerakkody R, J UK-I, Gaunt ME, Boyle JR, Li ZY, Miller SR, Graves MJ, Gillard JH. Utility of USPIO-enhanced MR imaging to identify inflammation and the fibrous cap: A comparison of symptomatic and asymptomatic individuals. Eur J Radiol. 2008.

16. Versluis A, Bank AJ, Douglas WH. Fatigue and plaque rupture in myocardial infarction. J Biomech. 2006;39(2):339-347.

17. Bank AJ, Wilson RF, Kubo SH, Holte JE, Dresing TJ, Wang H. Direct effects of smooth muscle relaxation and contraction on in vivo human brachial artery elastic properties. Circ Res. 1995;77(5):1008-1016.

18. Li ZY, Howarth S, Trivedi RA, JM UK-I, Graves MJ, Brown A, Wang L, Gillard JH. Stress analysis of carotid plaque rupture based on in vivo high resolution MRI. $J$ Biomech. 2006;39(14):2611-2622.

19. Li ZY, Howarth SP, Tang T, Gillard JH. How critical is fibrous cap thickness to carotid plaque stability? A flow-plaque interaction model. Stroke. 2006;37(5):11951199.

20. Li ZY, Howarth SP, Tang T, Graves MJ, J UK-I, Trivedi RA, Kirkpatrick PJ, Gillard JH. Structural analysis and magnetic resonance imaging predict plaque vulnerability: a study comparing symptomatic and asymptomatic individuals. J Vasc Surg. 2007;45(4):768-775.

21. Cheng GC, Loree HM, Kamm RD, Fishbein MC, Lee RT. Distribution of circumferential stress in ruptured and stable atherosclerotic lesions. A structural analysis with histopathological correlation. Circulation. 1993;87(4):1179-1187.

22. Tang D, Yang C, Zheng J, Woodard PK, Sicard GA, Saffitz JE, Yuan C. 3D MRIbased multicomponent FSI models for atherosclerotic plaques. Ann Biomed Eng. 2004;32(7):947-960. 
23. Loree HM, Kamm RD, Stringfellow RG, Lee RT. Effects of fibrous cap thickness on peak circumferential stress in model atherosclerotic vessels. Circ Res. 1992;71(4):850-858.

24. Imoto K, Hiro T, Fujii T, Murashige A, Fukumoto Y, Hashimoto G, Okamura T, Yamada J, Mori K, Matsuzaki M. Longitudinal structural determinants of atherosclerotic plaque vulnerability: a computational analysis of stress distribution using vessel models and three-dimensional intravascular ultrasound imaging. $J$ Am Coll Cardiol. 2005;46(8):1507-1515.

25. Trivedi RA, JM UK-I, Graves MJ, Horsley J, Goddard M, Kirkpatrick PJ, Gillard JH. MRI-derived measurements of fibrous-cap and lipid-core thickness: the potential for identifying vulnerable carotid plaques in vivo. Neuroradiology. 2004;46(9):738-743.

26. Trivedi RA, Mallawarachi C, JM UK-I, Graves MJ, Horsley J, Goddard MJ, Brown A, Wang L, Kirkpatrick PJ, Brown J, Gillard JH. Identifying inflamed carotid plaques using in vivo USPIO-enhanced MR imaging to label plaque macrophages. Arterioscler Thromb Vasc Biol. 2006;26(7):1601-1606. 
Figure 1
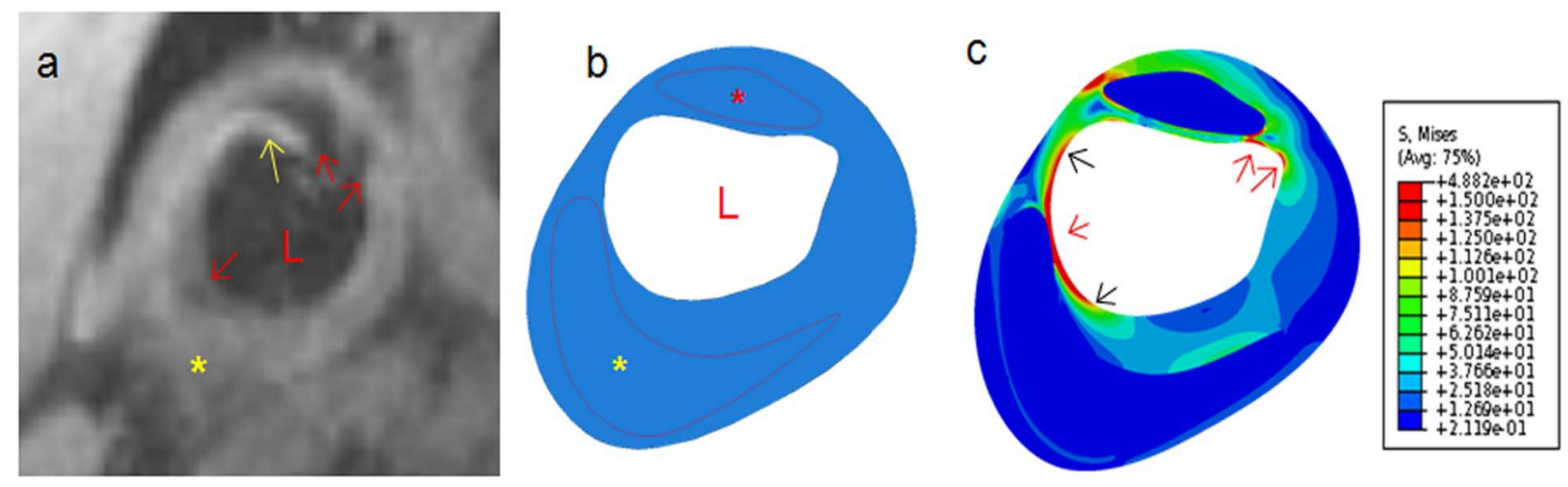
Figure 2
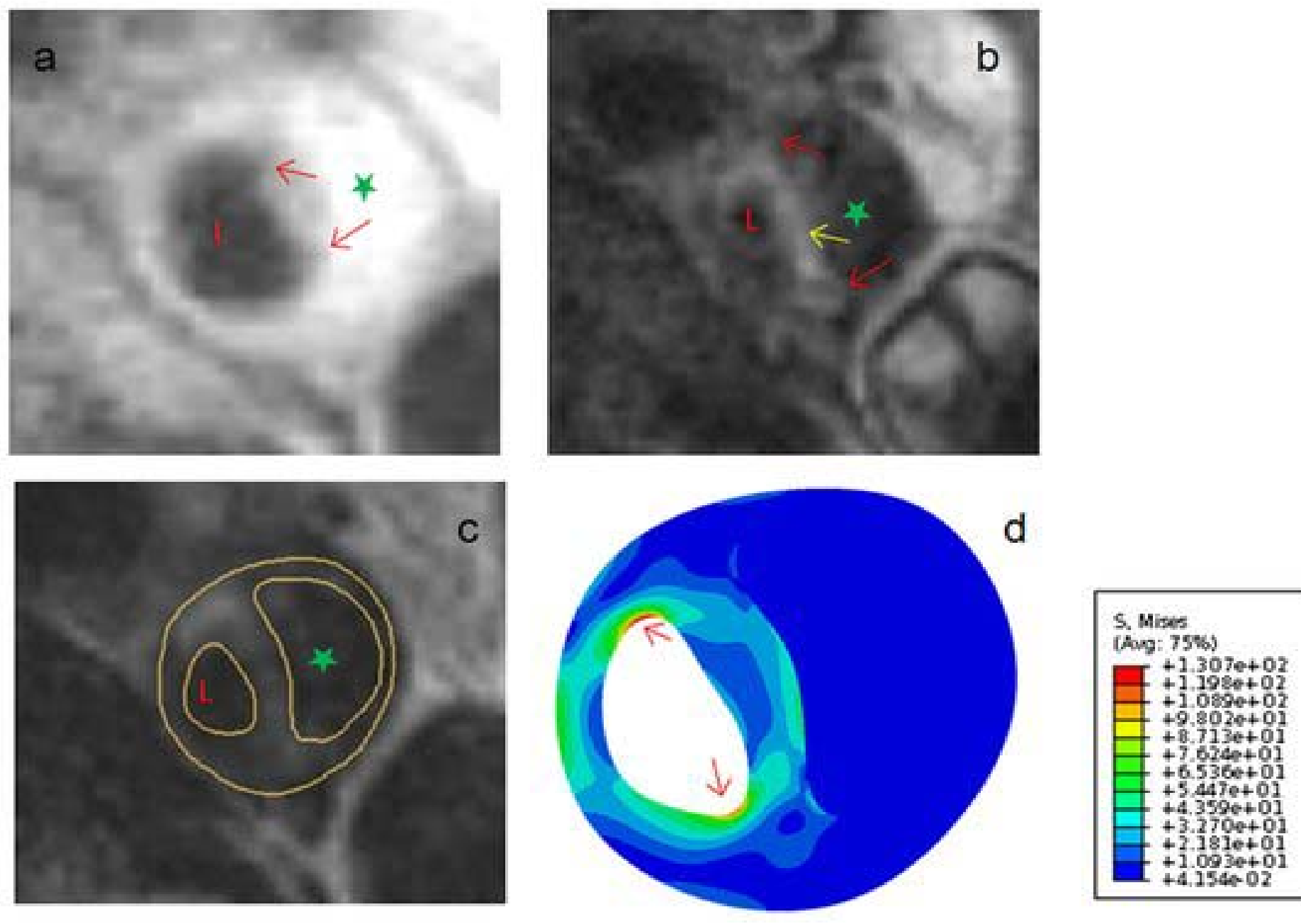